\title{
The role of mobile devices in the academic life of postgraduate students
}

\author{
David Kayode Baiyeshea BSc, GDip, MSc \\ 'Nottingham Business School, Nottingham Trent University, UK)
}

\begin{abstract}
This research will aid organizations in identifying opportunities for improvements and developments that will remain relevant as students' evolve from academic to professional life. Organizations will be enlightened on the impact mobile devices have on students, and how these devices could be helpful and some damaging to the welfare of students. Additionally, even though scholars have carried out various researches on mobile devices and students, focus has been based majorly on the role mobile devices plays in student's social life rather than academic life; this then is the gap this research aims to bridge.
\end{abstract}

Keywords: postgraduate students, mobile devices, organizational performance, professional Life

\section{Introduction}

Mobile devices and the ability to access data and information remotely used to be unrealistic concepts, but due to the technological developments in the $21^{\text {st }}$ century it is now a reality (Green, 2002). In the world today, wireless technology has created a platform for the use of mobile devices. Furthermore what makes the mobile devices more significant is the wide array of opportunities which it provides ranging from communication, education, transactions to entertainments (Adachi, 2001). In line with the increasing popularity of the mobile devices in offering the aforementioned benefits it has now become a common tool that is widely accepted by students and integrated into their everyday lives. Kukulska-Hulme\& Pettit (2006) stated that within the mainstream literature of technology appropriation among students, there have been attempts to describe the ways that students are adopting and using mobile devices. However there has been little understanding of the reasons for the high level of use or the opportunities for improvements and designs of new technologies that will further support students' lifestyles (Carroll et al, 2002; DeGagne \& Wolk, 2007). Therefore the purpose of this research is to ascertain what role mobile devices currently play in the academic life of postgraduate students and how their experiences of these mobile devices to date, can inform in the development of future innovation in the work place.

1.1 Research questions and objectives:

1.1.1 Research questions

- What are the types of mobile devices that are being used mostly by students?

- How and in what ways do students use the mobile devices in relation to academics?

- What are the major concerns and issues such as security or privacy in students' usage of the mobile devices?

- What are students' anticipations of the mobile devices in relation to future work activities?

\subsubsection{Research objectives}

- To examine which particular types of mobile devices are generally used by students.

- To investigate how and in what ways students' use these mobile devices in relation to academics.

- To detail the concerns and issues such as security or privacy students' encounter in their usage of mobile devices

- To explore students' expectations of mobile devices in relation to work activities

\section{Literature review}

To begin a study of student's use of mobile devices, it is important to define a typical student and what characteristics they possess. According to Margaryan, Littlejohn and Vojt (2011) the majority of university students are now part of a generation born after 1980 and are labelled as 'Digital Natives'. This generation grew up with access to computers and the internet which makes them inherently technology-savvy (Margaryan, Littlejohn and Vojt, 2011). According to DeGagne and Wolk (2007) there is a lot of information pertaining to the advantages and disadvantages of the adoption of mobile devices by university students, but information regarding student's use and opinions are sparse. Similarly, a study conducted by Demb et al (2004) found that information that describes students' experiences of the mobile devices particularly in the academic context is 
limited. Carroll et al (2002) noted that students' experiment with mobile devices especially if they are perceived convenient, affordable and support activities such as style and fashion. The limitation of this research however, is that students' opinions are based solely on the quality of their experiences of mobile devices in their social life; it does not examine its academic and societal role.

Furthermore Nagler and Ebner (2009) argued that the adoption of technology and mobile devices by students is context sensitive, that is students' adoptions of these devices are based on cost, familiarity and immediacy. Nonetheless, in their research, emphasis was based on the types of technologies used by students rather than the extent to which students use them. Alzaidiyeen et al (2011) suggested that there are a number of distinctive characteristics of mobile devices such as portability and accessibility that has made it an integral part of student's everyday life making it possible for them to access data and information wherever they are. Regardless of the capabilities of mobile devices expressed by Alzaidiyeen et al (2011), Kabel (2012) stated that students live in scattered spaces and the way they use mobile devices to undertake work, education and social activities cannot be fully comprehended. Moreover Bowden (2008) argued that it is important for students to be able to use mobile devices proficiently, because it is developing to become a common tool for harnessing knowledge. He further stated that students' must not only master how to use these tools, butthey must be culturally sensible in using the tools for accessing information and assembling knowledge. In agreement with Bowden (2008), Goldin and Katz (2008) found that just the way reading and writing is essential in paper based contexts, mobile devices are essential in the lives of students. This is because we now live in a digital society; in which employers want employees who are digitally literate. Meuller et al (2012) further described innovation and invention in the $21^{\text {st }}$ century as the ability to harness different academia, social and technological networks and students use mobile devices as cognitive tools for achieving this. DeGagne and Wolk (2007) however, in their research described students as being slower in developing adequate skills in using the wireless technology platform, which enhances the adoption of mobile devices for support in their academic activities. DeGagne and Wolk (2007) found that the attributes of students are more observable in the non-academic context than academic sceneries, even though same devices are available to them in both spheres. Also the more mobile devices students use the more fragmented student's information become (ibid).

Delving from the preceding, another imperative aspect of mobile devices and students' adoption is security. Previous studies have shown that students' awareness of the issues related to security in the adoption of mobile devices is limited. Beech and Geelhoed (2002) assert that a major constraint intrinsic to mobile devices is security. According to Beech and Geelhoed (2002) mobile devices are not espoused by students with security as a top priority which makes them vulnerable to attacks from hackers. Tan and Aguilar (2012) stated that student's awareness of security information issues in their usage of mobile devices continues to be poor. This is indeed a concern because student's use mobile devices pervasively for communicating, socialising, as well as working on their academic assignments. DeGagne and Wolk (2007) posit that students' show negligence to security issues and adopt mobile devices based on exposure to ideas that are in accordance with their interests, needs and attitudes. Contrary to DeGagne and Wolk (2007), Tan and Aguilar (2012) believe that even though students do not take adequate precautions to mitigate against security vulnerabilities, differences exist in student's perceptions based on their academic major. They further discovered that science students tend to be more cautious than business and social science students.

In view of all these findings from various researchers, it is then the purpose of this research to provide a better understanding on the linkage between student's academic life and their usageof mobile devices. Furthermore this research will aid organisations in identifying opportunities for improvements and developments that will remain relevant as students' evolve from academic to professional life. Organisations will also be enlightened on the impact mobile devices have on students, and how these devices could be helpful and some damaging to the welfare of students. Additionally, even though researchers have carried out various researches on mobile devices and students, focus has been based majorly on the role mobile devices plays in student's social life rather than academic life. This then is the gap this research aims to bridge. Additionally, apprehensions such as security which is stated by Tan and Augliar (2012), to be a vital part of mobile devices usage in the $21^{\text {st }}$ century will be analysed from student's perspectives. This will further provide an understanding of the major concerns students' have and are aware of concerning their usage of these devices.

\section{Findings and discussions}

The research findings from the questionnaires and interviews are discussed in this section. A face to face questionnaire was administered to MSC management students in NTU. A total of 50 questionnaires was distributed and retrieved. Also to effectively arrive at a conclusion 9 students were interviewed and their answers were recorded and transcribed to uncover additional relevant information that buttresses the questionnaire analysis. 


\subsubsection{Data presentation and analysis}

3.1.2 Demographics of participants

From the questionnaire survey there were 25 males and 25 females giving a total of 50 samples. Additionally majority (63.3\%) of the respondents were aged 21-23. The main aim of the question was to be able to group respondents into categories based on their ages to know those who were born in or after 1980 and those who are likely to be born before 1980. It can be concluded based on the findings that all the students were born in and after 1980 indicating that they are digitally versatile. Gardner and Eng (2005) found that majority of students are now part of a generation born just after 1980 and are more unique, ambitious and optimistic than those born before 1980, because they are able to easily adapt to different learning styles, especially one involving the use of technology and mobile devices. Margaryan, littleJonh and Vojt (2011) in support of Gardner and Eng (2005) believe that those born in or after 1980 not only understand technology but through their exposure tothese technologies have developed a sort of "fluency" in multiple media adopting more than one mobile device at the same time.

\subsubsection{Students' usage and experiences}

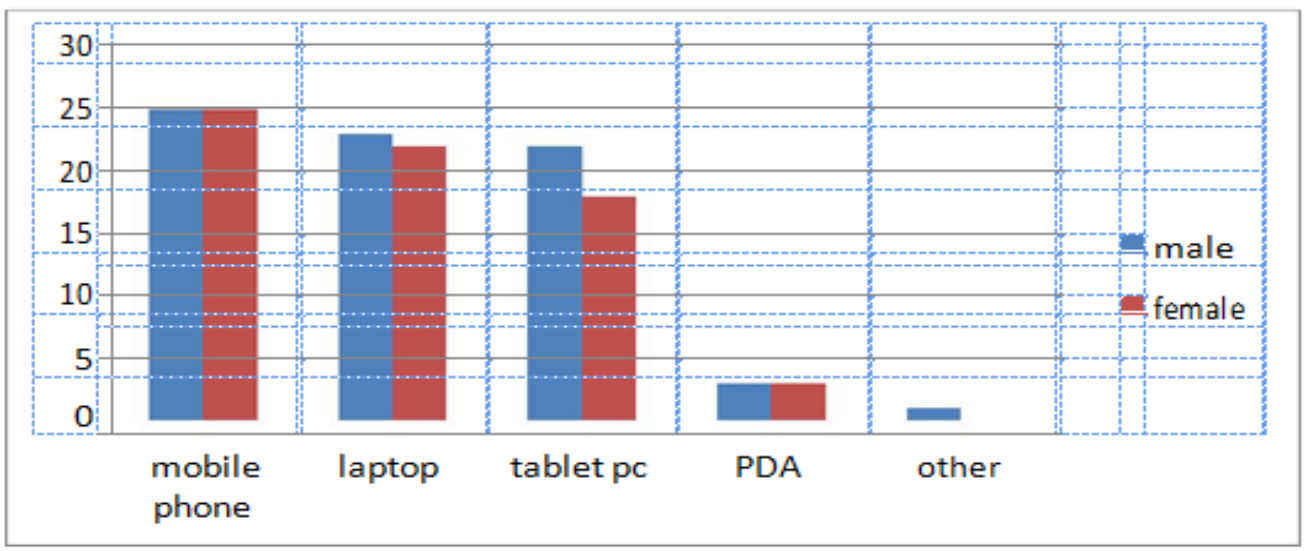

Fig1. Number of mobile devices

The above data representation describes the number of mobile devices owned by respondents according to gender distribution. Not surprisingly, all respondents had mobile phones, however The male group reported $92 \%$ laptops, $88 \%$ tablets, $12 \%$ PDA and $4 \%$ others while the female group reported $88 \%$ laptops, $72 \%$ tablets and $12 \%$ PDA. These results indicated that there were some statistical differences in the number of mobile devices ownership among the gender groups favouring the males. It can be concluded based on these findings that males exhibited higher attitudes towards mobile devices than females. DeGagne and Wolk (2007) believe that males tend to have more mobile devices than females. He found that male students utilize the wireless technology platform enhanced by mobile devices differently than females especially for innumerable non-academic reasons such as gambling and online monitoring of sports. While Jones et al (2010) believe that as far as mobile devices are concerned male and female students have the same high level of skills and use, but male students are more comfortable with specialised technologies than females. Consequently, based on the findings it can be assumed that male students are far more confident with mobile devices female students.

\subsubsection{Features of mobile devices (male)}

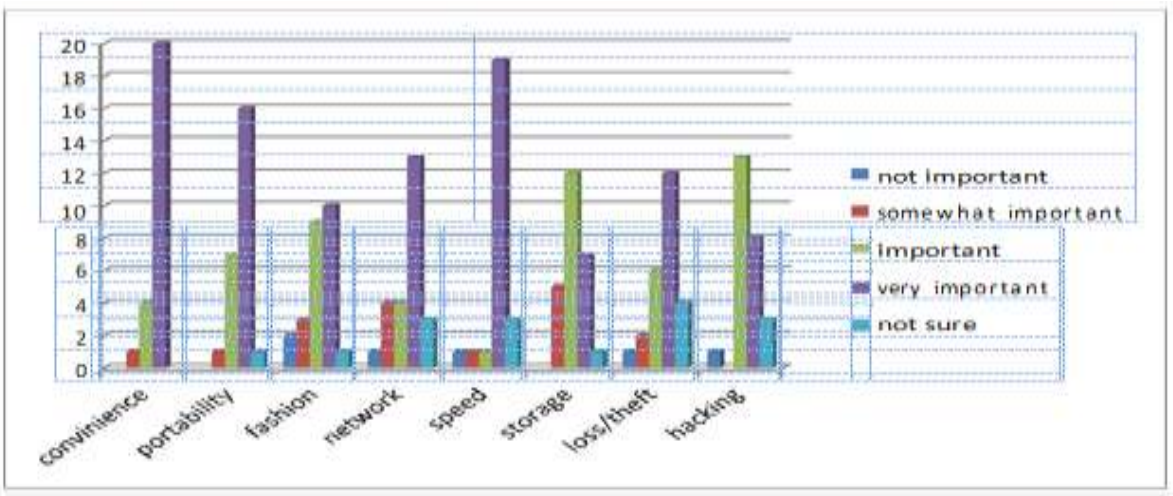

Fig2. Male responses to reatures or mobile devices 


\subsubsection{Features of mobile devices (female)}

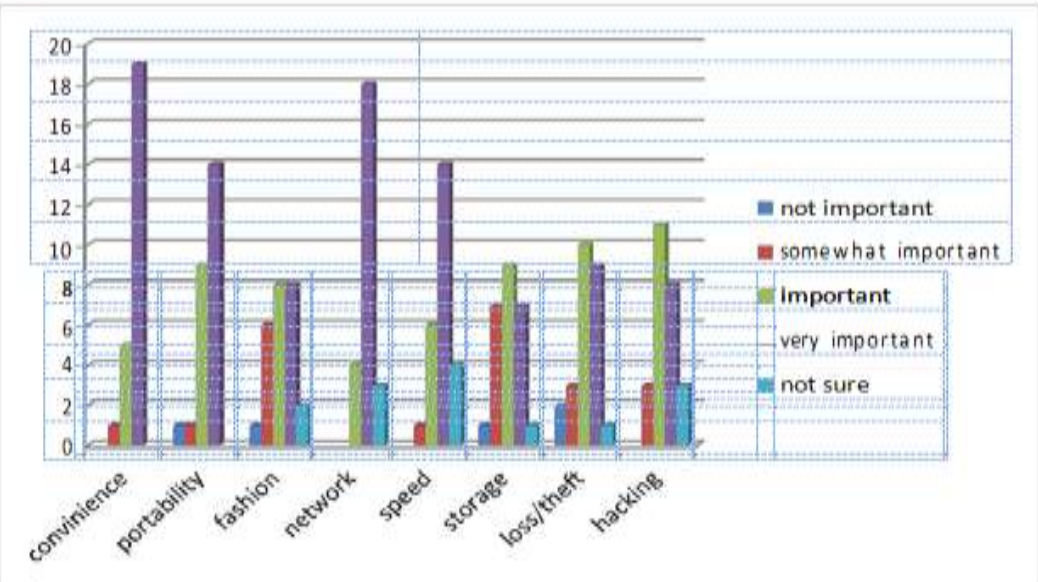

Fig3. Female responses to features of mobile devices

The chart above (Fig 2 and Fig 3) describes male and female responses to rating of features of mobile devices in order of preference and importance. The result shows that both gender place more emphasis on convenience, portability, network stability and speed. The result indicates that $80 \%$ male and $76 \%$, female specified convenience as a very important featurewith a slight statistical difference favouring the male group. Additionally the result shows that there is significant difference between males (64\%) and females $(56 \%)$ who regard portability as a very important feature. On the other hand females (72\%) exhibited more attitudes than males $(52 \%)$ towards network stability describing it as very important. The result revealed that $76 \%$ male and $56 \%$ female placed emphasis on speed with the male respondents having more enthusiasms. These findings are in line with Alzaidiyeen et al (2011) who stated that mobile devices have become an integral part of the lives of students because of its distinctive characteristic features which include portability, accessibility and convenience. Similarly Carroll et al (2002) found that students' experiment with mobile devices especially if they are perceived convenient, affordable and support activities such as style and fashion. Moreover Alzaidiyeen et al (2011) and Carroll et al (2002) did not use gender distribution in their analysis, the findings from this research further reveals that male students show more enthusiasms towards features of mobile devices including fashion which was an astounding finding, more male students $40 \%$ indicated it as very important than females $32 \%$.

\begin{tabular}{|l|l|l|l|l|l|}
\hline & strongly & & & & strongly \\
\hline Purpose & disagree & disagree & neutral & agree & agree \\
\hline Contact & & & & & \\
\hline classmates & & & & & \\
\hline and tutors & $2 \%$ & & $30 \%$ & $34 \%$ & $34 \%$ \\
\hline Download & & & & & \\
\hline academic & & & $40 \%$ & $24 \%$ & $28 \%$ \\
\hline material & $2 \%$ & $6 \%$ & & & \\
\hline Store & & & & & $22 \%$ \\
\hline academic & & $16 \%$ & $22 \%$ & $40 \%$ & \\
\hline material & & & & & $24 \%$ \\
\hline Do & & $20 \%$ & $18 \%$ & $30 \%$ & $16 \%$ \\
\hline assignment & $8 \%$ & $18 \%$ & $20 \%$ & $40 \%$ & $32 \%$ \\
\hline lecture notes & $6 \%$ & & & & \\
\hline Check & & $8 \%$ & $22 \%$ & $38 \%$ & $26 \%$ \\
\hline academic info & & & & & \\
\hline assist my & & $14 \%$ & $18 \%$ & $42 \%$ & $34 \%$ \\
\hline study & & & & & $10 \%$ \\
\hline Access latest & & $14 \%$ & $24 \%$ & $28 \%$ & $28 \%$ \\
\hline news & & $26 \%$ & $14 \%$ & & \\
\hline Job search & $22 \%$ & $\mathrm{n}$ & & & \\
\hline
\end{tabular}

Table 1: For what purposes do you use your mobile devices? Please rate the following statements

The table depicts the agreement distribution of participants. Students were asked to rate their opinions on how mobile devices help in achieving specific academic related tasks as stated in the table. The results show that on the average most students agree that mobile devices to some extent help in achieving academic related tasks. $42 \%$ of respondents agree that mobile devices aid in their study. Additionally $34 \%$ of respondents 
strongly agree that mobile devices allow them, keep in contact with their classmates and tutors. There is, however some significant element of strong disagreement with the comment involving using mobile devices for job search. $22 \%$ of respondents, the strongest single group to strongly disagree that they use mobile devices for searching for jobs. Implying that, perhaps students do not really depend on mobile devices for job search. Based on the findings it can be assumed that majority of students accept and use mobile devices for learning purposes and this may be due to the specific features of mobile devices such as convenience, portability and immediacy.

Table 1 also confirms the interview analysis (see appendix) that most students believe mobile devices aid in their experiences in usage for academic related work.

'Ok, I would like to say that my mobile devices have been very helpful. I can carry my ipad anywhere; I can also carry my laptops anywhere and access information at any time. This for me is a major development. Because when am in a gathering or in a mood to brainstorm about school work I can just pick up my ipad and browse" (participant, F).

These assertions give credence to the work of Alzaidiyeen et al (2011) who found that students' adoption of mobile devices is due to its distinctive characteristics. Meuller et al

(2012) believe that mobile technology is a cognitive tool used by students for supporting learning activities.

\subsubsection{Student's concerns on mobile devices}

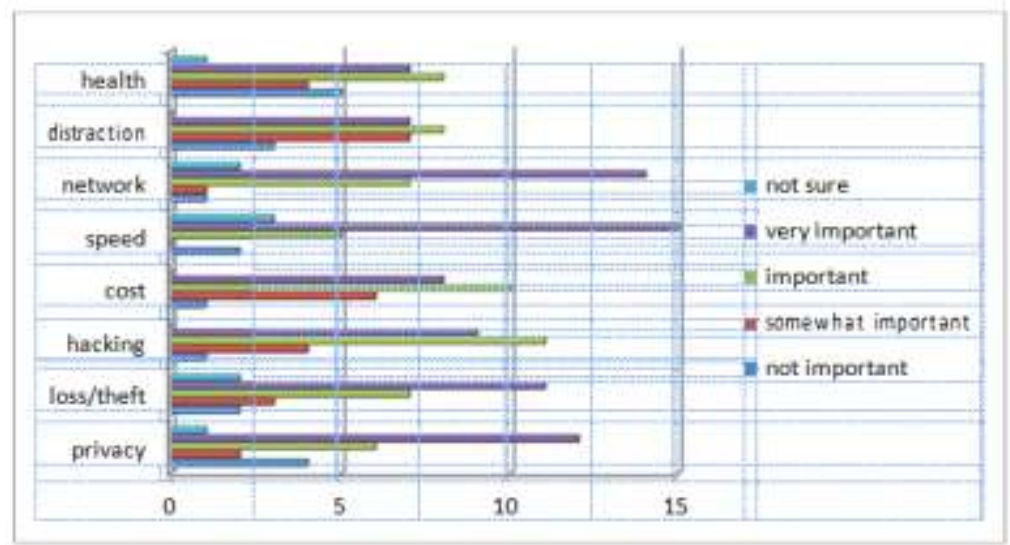

Fig4. Male concerns on mobile devices

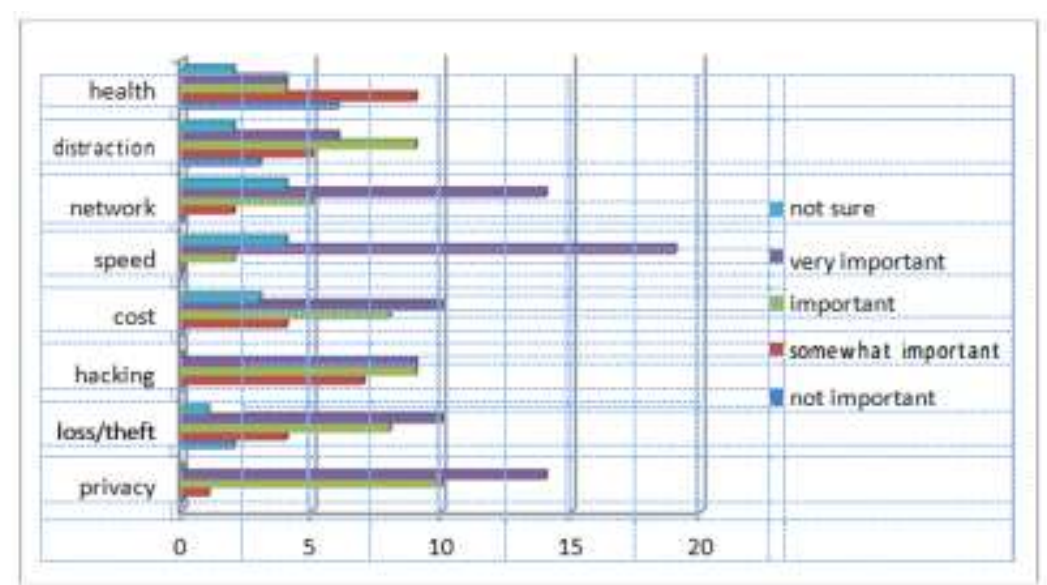

Fig5. Female concerns on mobile devices

In order to substantially explore the major trepidations students have in their usage of mobile devices, they were asked to rate the concerns highlighted in the charts (Fig 4 \& Fig 5) above according to the level of importance. From the results it can be observed that majority of respondents are more concerned about privacy, speed and network issues. The male group reported $48 \%$ privacy, $60 \%$ speed, $56 \%$ network and the female group reported $56 \%$ privacy, $76 \%$ speed and $56 \%$ network. From the quantitative results, despite the females being more 
concerned about speed and privacy, it can be concluded that gender has little influence on the dealings students have with mobile devices due to the propinquity in the findings. Additionally the semi structured interview further reveals certain concerns students have in their usage of mobile devices that were not expressed in the questionnaires.

'Ermmm, the major drawback for me is compatibility, because some files, the formats are not supported by ipad so thats my main issue, then sometimes network stability Network goes off and is not stable'. (Participant, F)

'My main concern is the long life of my mobile devices because I want to use it for a long time For instance, battery life and durability of the device"'. (Participant, $H$ )

The interview analysis further revealed that respondents even had futuristic aspirations towards mobile devices.

'Even in the future I am presuming that mobile devices will be developing even further from whatever devices we have now. From the keypad it developed to touch, now I know probably is going to be holographic sort of technology which we will look forward to ". (Participant D)

As a result of the analysis on the concerns participants have towards their adoption of mobile devices, it can be inferred that participants pay little emphasis on security related issues especially hacking (male $44 \%$ loss/theft, $36 \%$ hacking, and female $40 \%$ loss/theft, 36\% hacking). They would rather place their judgement about concerns on speed, network and privacy. Comparatively, the interview analysis also indicates additional concerns such as compatibility, durability and battery life that students' are aware of and concerned about in their usage of mobile devices. These results support the findings of Tan and Aguilar (2012) who believed that student's awareness of security related issues in their usage of mobile device are little. Beech and Geelhoed (2002) posit that mobile devices are not adopted by students with security as a top priority and this makes them vulnerable to attacks fromhackers. Besides, DeGagne and Wolk (2007) discovered that students' show laxity to security issues and adopt mobile devices based on exposure to notions that are appealing to them.

\subsubsection{Summary Research findings}

\section{To examine which particular types of mobile devices are generally used by students.}

It can be inferred from the findings that majority of respondents use multiple mobile devices ranging from mobile phones to tablets and PDAs, with an indication of the male respondents having more mobile devices than females.

2. To investigate how and in what ways students' use these mobile devices in relation to academics. The findings from the study shows that respondents find mobile devices helpful for communicating and accessing relevant academic information with a total of $76 \%$ respondents stipulating that it aids in their study.

\section{To detail the concerns and issues such as security or privacy students' encounter in their usage of mobile devices}

The analysis from the findings shows that students have lots of concerns regarding their dealings with mobile devices and such concerns include privacy, speed, and network stability. The interview analysis indicates that respondents also have concerns on battery life, compatibility and durability. However security related issues received little attention with respondents not laying much emphasis on them.

\section{To explore students' expectations of mobile devices in relation to work activities}

It can be concluded from the study that student's usage of mobile devices is based on some of its specific features which include convenience, portability and accessibility. And innovations in these features will further influence student's adoption even in relation to work activities.

\section{Reflection}

This research is inductive in nature because it seeks to generate a theory through investigations and observations; thereby my team and I discovered that the qualitative approach seemed appropriate because it is based on non-numeric data, in which findings areexpressed using words. However the research also required numeric data which led to the use of a mixed method approach in which the qualitative and quantitative approaches were used. Data for the qualitative approach was collected using semi-structured interviews and data for the quantitative approach was gathered through questionnaires. The research team also discovered that the study was both exploratory and explanatory and it is in the light of this, that the case study design was used. 
Additionally the case study design was adopted because it involves an intensive and detailed analysis of a single case in its real life context (Robson, 2002). One of the major challenges the team faced as a group was attaining conformity in formation of questions for the study as each member had different ideas on what and how the questions should be articulated. As the team leader I accorded each of us in the team the responsibility of formulating questions, and after careful considerations specific questions were selected, collated and itemised for the study. The research process also increased my analytical and critical thinking skills as I was able to link theoretical concepts to real life situations.

The criteria for the sample population was already known, which is that participants must be MSC management students in NTU, however due to inability to gain access to the database of all the students in MSC management, it was deliberated among team members and a decision was made to use a purposive nonprobability sampling. Therefore a sample size of 25 males and 25 females were selected for the quantitative aspect while 9 were selected for the qualitative.

\subsection{Validity and reliability}

Validity according to Bryman and Bell (2007) evaluates the level of relation between theoretical concepts and empirical work. This study adapted items from theoretical concepts of previous researchers to increase the validity of the findings. The data collection method for this research also confirms a realistic reliability, because face to face interviews and questionnaires have a low degree of respondents bias compared with methods such as telephone or mailed survey (Czaja and Blair, 2004).

4.2 Ethical considerations: In order to avoid ethical issues such as confidentiality, anonymity and lack of informed consent, participants were made to understand what the research was all about by giving them a detailed explanation. Additionally they were given an information sheet and a consent form(see appendix) to read and sign. Participants were made to understand that they can opt out of the research at any given time. To preserve the names of participants and prevent the information given from being traced back to them an alias was used instead of their real names.

\subsection{Limitation of study}

$\square \quad$ The sample was geographically limited. Data collected in other parts of the UK may produce different results.

$\square$ Participants were limited to students of NTU, and it was observed during the analysis that certain terminologies in the questionnaires were not understood by the participants, it is possible that this might have influenced findings from this study. Additional research will be needed to examine this area.

$\square \quad$ Another limitation of the study is time constraint. The time allocated for data collection is limited. Also the findings from this study may not be generalised to a more broad population as the research is exploratory and has concentrated on MSC management students in NTU.

\section{Conclusion}

The study has provided an insight into the role mobile devices play in the academic life of postgraduate students. The study has also aided in the identification of relevant features, anticipations and concerns students have in their usage of mobile devices. Previous researchers have argued and noted that the impact of mobile devices on students cannot be overemphasised. While some believe that students adopt these devices because of its distinctive characteristic such as portability and accessibility (Carroll et al, 2002; Alzaidiyeen et al, 2011), others believe that students' adoption is context sensitive based on notions that are appealing to them (Nagler and Ebner, 2009). This study observed the various levels of importance, attributes and concerns that students attach to mobile devices through interviews and questionnaires. Elements such as portability, convenience, accessibility, privacy, network stability and speed generated the most intense attributes influencing students' judgement on mobile devices. Element such as security do not really serve as trigger to students' adoption of mobile devices. Furthermore students in the sample seemed to exhibit differences in aspects of mobiles devices based on gender distribution. The research revealed that male students tend to have more mobile devices than female students and each gender had certainfeatures that were specifically appealing to them. Based on the findings from the study, it can be said that students had futuristic aspirations towards the features of mobile devices and the development of innovation in these features will further influence students' usage when they evolve from being learners to workers. Finally the research was able to answer all the research questions and objectives even though the time and scope of the study posed a challenge. 


\section{References}

[1] Alzaidiyeen, N. J., Abdullah, A. G. K., Al-Shabatat, A. M., and Seedee, R. (2011). The information aged: examination of university students' attitudes towards personal digital assistants (PDAS) usage in terms of gender, age and school variables. Turkish online journalof education. 10(3). Pp. 287-295.

[2] Adachi, F. (2001). Wireless Past and Future--Evolving Mobile Communications Systems.

[3] IEICE transactions on fundamentals of electronics, communications and computer sciences, 84(1), 55-60.

[4] Bryman, A., and Bell, E. (2007). Business Research Methods $2^{\text {nd }}$ ed. Oxford: Oxford University Press.

[5] Beech, S. L., \& Geelhoed, E. N. (2002, March). User attitudes towards wireless technology: 802.11 b. In HPL. Retrieved from: https://www.hpl.hp.com/techreports/2002/HPL-2002-22.pdf [Accessed 9th April 2013].

[6] Czaja, R. and Blair, J. (2005). Designing Surveys: a guide to decisions and procedures.

[7] Thousand Oaks, California: Pine Forge Press.

[8] Carroll, J., Howard, S., Vetere, F., Peck, J., \& Murphy, J. (2002). Just what do the youth of today want? Technology appropriation by young people. Proceedings of the 35th AnnualHawaii International Conference on system Sciences. HICSS. pp. $1777-1785$.

[9] Demb, A., Erickson, D., \& Hawkins-Wilding, S. (2004). The laptop alternative: Student reactions and strategic implications. Computers \& Education, 43(4), pp. 383-401.

[10] DeGagne, M., Wolk, R. (2007) "Unwired: student use of technology in the ubiquitous computing world", Information Systems Education Journal, Vol.5 (13). Pp.3-14.

[11] Goldin, C. and Katz, L.F., (2008). The Race between Education and Technology. Cambridge, MA: Harvard University Press.

[12] Gardner, S., \& Eng, S. (2005). What students want: Generation Y and the changing functionof the academic library. Portal: Libraries and the Academy, 5(3), pp. 405-420.

[13] Green, N. (2002). On the move: technology, mobility, and the mediation of social time and space. The information society, 18(4), 281-292.

[14] Jones, C., Ramanau, R., Cross, S. and Healing, G., (2010).Net generation or Digital Natives:Is there a distinct new generation entering university? Computersand Education, Vol 54(3), pp. 722-732.

[15] Kuhn J., Lehner F., Lehmann H. (2003). Scenarios of a Mobile Future: Findings from a Grounded Delphi Study. In The Stockholm mobility Roundtable 2003, [available online http://www.jkuhn.de/veroeffentlichungen/jkuhn-stockholm-2003-article.pdfacessed 7th April, 2013].

[16] Kabel, M.L (2012) Interfaces that Help Students Think: Supporting Cognition and DigitalLiteracy with Mobile Apps [Online]. Retrieved from:http://iat.ubalt.edu/wp-content/uploads/2012/06/kabel-thesis.pdf [Accessed 11th April 2013].

[17] Kukulska-Hulme, A., \& Pettit, J. (2009). Practitioners as innovators: Emergent practice inpersonal mobile teaching, learning, work and leisure. Mobile learning: Transforming thedelivery of education and training, 135-155.

[18] Mueller, J. L., Wood, E., De Pasquale, D., \& Cruikshank, R. (2012). Examining Mobile Technology in Higher Education: Handheld Devices In and Out of the Classroom. International Journal of Higher Education, 1(2), p43-54.

[19] Margaryan, A., Littlejohn, A., \& Vojt, G. (2011). Are digital natives a myth or reality? University students' use of digital technologies. Computers \& Education, 56(2), pp. 429-440.

[20] Robson, C. (2002). Real world research: a resource for social scientists and practitioner-researchers (Vol. 2). Oxford: Blackwell.

[21] Tan, M. and Aguilar, K.S, (2012) "An investigation of students' perception of Bluetooth security", Information Management \& Computer Security, Vol. 20(5), pp.364 - 381 